East African Medical Journal Vol. 86 No. 10 October 2009

MORPHOLOGICAL AND FUNCTIONAL TRAITS OF MALOCCLUSION IN 3-5 YEAR-OLDS IN MOSHI, TANZANIA

D.S. Rwakatema, DDS, MDS, Lecturer, Department of Dentistry, Kilimanjaro Christian Medical College, Tumaini University, P.O. Box 3010, Moshi, Tanzania and P.M. Ng'ang'a, BDS, MSD, PhD, Associate Professor, Department of Paediatric Dentistry and Orthodontics, Faculty of Dental Sciences, University of Nairobi, P.O. Box 19676 - 00202, Nairobi, Kenya

Request for reprints to: Dr. D.S. Rwakatema, Department of Dentistry, Kilimanjaro Christian Medical College, Tumaini University, P.O. Box, 3010, Moshi, Tanzania

\title{
MORPHOLOGICAL AND FUNCTIONAL TRAITS OF MALOCCLUSION IN 3-5 YEAR-OLDS IN MOSHI, TANZANIA
}

\author{
D.S. RWAKATEMA and P.M. NG'ANG'A
}

\begin{abstract}
Objective: To assess the morphological and functional traits of malocclusion.

Design: Cross-sectional study.

Setting: Moshi Municipality, Kilimanjaro region, Tanzania.

Subjects: Examination for occlusal traits was done on 372 randomly selected 3-5-year olds (157 males and 215 females).

Results: The overall prevalence of malocclusion was $26.9 \%$. Females had significantly more occlusal anomalies than males. The flush terminal plane $(93.8 \%)$ was the commonest anteroposterior relation. Excessive maxillary overjet and deep-bite occurred in 5.1\% and $21.5 \%$ of the children respectively. Reverse overbite $(1.9 \%)$, frontal open-bite $(1.6 \%)$, lateral open-bite $(0.8 \%)$ and posterior cross-bite $(0.3 \%)$ were relatively rare. Harmful oral habits were uncommon in this population. The sample mean for inter canine width in the maxilla was $31.1 \mathrm{~mm}(\mathrm{SD} \pm 2.72)$ and for the mandible $25.3 \mathrm{~mm}$ (SD \pm 2.46 ). Lack of natural spacing in the anterior segment of the maxilla occurred in $34.4 \%$ of the children and $33.6 \%$ in the mandible.

Conclusion: Generally, females had significantly more occlusal anomalies than males. The flush terminal plane was the commonest anteroposterior finding. Lack of natural spacing in the anterior segments and deep bite were common.
\end{abstract}

\section{INTRODUCTION}

Malocclusion may exert a negative influence on the general as well as the oral health of a child. Data indicate the occurrence of malocclusion to be universal; and traits vary between individuals and between ethnic groups $(1,2)$. Previous reports show that certain anomalies and traits in the primary dentition can appear in the permanent dentition (1). Early recognition of undesirable traits, anomalies and oral behaviour detrimental to the developing primary occlusion may enable simple interceptive measures (3), which in most cases do not need the services of an orthodontic specialist. Such intervention may prevent or alleviate full-fledged orthodontic treatment in the permanent dentition, which usually calls for specialist attention.

There are few studies on the occlusal status in the primary dentition of children in Tanzania and East Africa in general $(1,4)$. This makes it difficult to know to what extent interceptive orthodontics is necessary not only for clinical purposes but also for academic reasons. The purpose of this study, therefore, was to assess the morphological and functional traits of malocclusion in 3-5-year-olds in Moshi, Tanzania.

\section{MATERIALS AND METHODS}

This was a cross-sectional study involving preprimary school children aged 3-5 years (157 males and 215 females) in Moshi Municipality, Tanzania. Ethical clearance was sought from Tumaini University, Kilimanjaro Christian Medical College Ethics Committee in Moshi, Tanzania. A written informed consent was obtained from each of the parents/ guardians of the children who were examined. The subjects were randomly selected from 57 pre-primary nursery schools in Moshi municipality. Each pupil aged 3-5 years was identified through a register and assigned a number for random selection. A sample of 372 children was obtained. This sample constituted $3.8 \%$ of all the 3-5-year- olds in Moshi municipality. The children were examined in a classroom using natural light and with the aid of ordinary mouth mirrors and miniature standardised plastic rulers. One examiner (DSR) carried out all examinations. 
An assistant entered data in a pre-prepared form. The children were examined for prevalence of occlusal traits using the Bjork et al. (5) criteria with slight modification. The modification was in relation to the determination of anteroposterior second molar relation, intercanine widths, and spacing in the anterior segments and detrimental oral behaviour. Anteroposterior primary second molar relation was scored and grouped as a flush terminal plane, mild mesial step $(<2 \mathrm{~mm})$, severe mesial step $(\geq 2 \mathrm{~mm})$ or distal step. Maxillary and mandibular intercanine wid ths were measured directly in the oral cavity using a miniature plastic ruler. Detrimental oral behaviour was examined by looking for clinical signs on a child as described in the literature (6). Digital sucking was examined by looking for the appearance of any sign of redness, exceptionally clean, short fingernails on the sucked digit. Mouth breathing was examined by placing a butterfly shaped piece of cotton above the upper lip below the nostrils. Down flutter of the cotton ruled out mouth breathing. Lip biting was examined by looking for any sign of reddened irritated area below the vermillion border of the lip being bitten or accentuated mentolabial sulcus in case of the lower lip being bitten. Parents / guardians questionnaire in regard to the oral behaviour of their children was administered to augment these observations (Table 1).

Data were fed in the computer for analysis using Statistical Package for Social Sciences (SPSS) version 12.1 (7) and Epidemiology Information Package (Epilnfo) (8). TheKappa test was used toevaluateintraexaminer reproducibility of the qualitativevariables(9) and the related t-test for quantitative variables. Each tenth subject examined was subjected by the recorder for re-examination on each day of examination. Atotal of 44 subjects were re-examined by the end of data collection. ANOVA, Chi-square test and Fisher's exact test were used toevaluate for any significant differences between males and females on the mean intercanine widths and the prevalence of occlusal traits. A p-value $<0.05$ was considered significant.

\section{RESULTS}

Figure 1 illustrates the distribution of examined subjects according to age and gender. The intraexaminer reproducibility test for qualitative variables produced a Kappa score of 0.9 indicating high reproducibility. There was no significant difference in the reproducibility for quantitative variables $(p>0.05)$. The overall prevalence of malocclusion (inversion maxillary incisors, rotated tooth, bilateral distal step, bilateral severe mesial step, excessive maxillary overjet, mandibular overjet, increased deep-bite, frontal open-bite, lateral open-bite, posterior crossbite and scissor-bite) was $26.9 \%$ (Figure 2). Females had significantly higher occlusal anomalies than males $(\mathrm{P}<0.05)$. The bilateral flush terminal plane was found in the majority of the children (93.8\%). Excessive maxillary overjet $(5.1 \%)$, reverse overbite $(1.9 \%)$, lateral open-bite $(0.8 \%)$, frontal open-bite $(1.6 \%)$ and posterior cross-bite $(0.3 \%)$ were uncommon. Excessive deep bite $(21.5 \%)$ was relatively common and occurred more significantly in females than in males $(\mathrm{P}<0.05)$ (Table 2).

Figure 1

Overall distribution of occlusal anomalies in 372 children

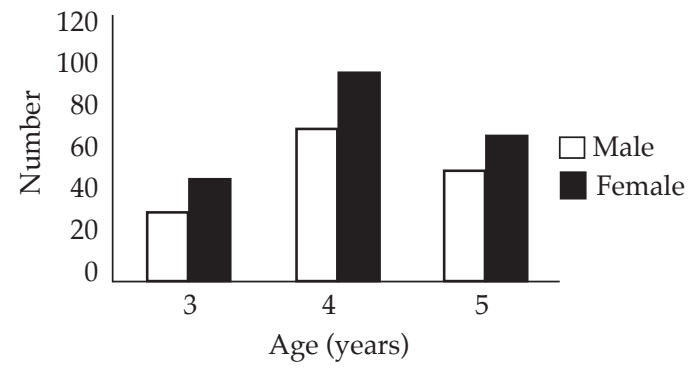

Figure 2

Distribution of children examined for morphological and functional traits of malocclusion by age and gender $(n=372)$

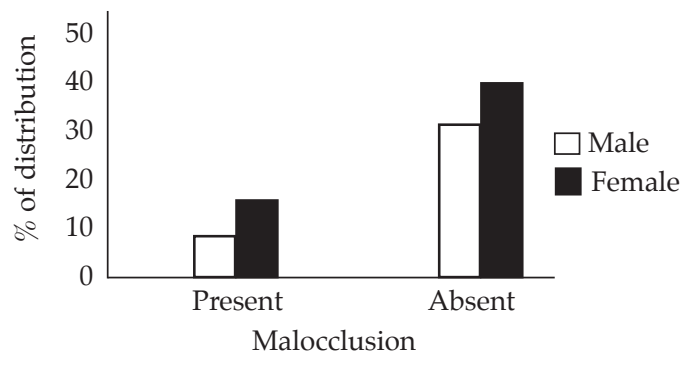

Table 1

Parent's/guardian's questionnaire administered to augment the criteria used in scoring oral habits for 3-5 year old children in Moshi Tanzania

I. Is your child still sucking his/her digit these days?

Yes

No

Has never sucked

II. Does your child breath through the mouth at all times?

Yes

No

Do not know / I have not observed

III. Does your child bite or suck the lips most of the time?

Yes

No

Do not know / I have not observed 
Table 2

Prevalence of morphological malocclusion traits in Moshi children (157 males, 215 females) $(n=372)$

\begin{tabular}{|c|c|c|c|c|c|c|c|}
\hline \multirow[b]{2}{*}{ Occlusal trait } & \multicolumn{4}{|c|}{ Gender } & & \multirow[b]{2}{*}{ P-value } \\
\hline & \multicolumn{2}{|c|}{$\begin{array}{l}\text { Male } \\
\text { No. }(\%)\end{array}$} & \multicolumn{2}{|c|}{$\begin{array}{l}\text { Female } \\
\text { No. }(\%)\end{array}$} & \multicolumn{2}{|c|}{$\begin{array}{l}\text { Total } \\
\text { No. }(\%)\end{array}$} & \\
\hline Inversion maxillary incisors & 2 & 0.5 & 4 & 1.1 & 6 & 1.6 & 1.00 \\
\hline Rotated tooth (estimated $15^{\circ}$ ) & 1 & 0.3 & 4 & 1.1 & 5 & 1.3 & 0.40 \\
\hline Malformation & 1 & 0.3 & 1 & 0.3 & 2 & 0.5 & 1.00 \\
\hline Distal step (right and left) & 2 & 0.5 & 2 & 0.5 & 4 & 1.1 & 1.00 \\
\hline Unilateral mild mesial step $(<2 \mathrm{~mm})$ & 1 & 0.3 & -2 & 0.5 & 3 & 0.8 & 1.00 \\
\hline Bilateral mild mesial step $(<2 \mathrm{~mm})$ & 3 & 0.8 & -3 & 0.8 & 6 & 1.6 & 0.70 \\
\hline Bilateral severe mesial step $(\geq 2 \mathrm{~mm})$ & 6 & 1.6 & -0 & & 6 & 1.6 & ${ }^{*} 0.00$ \\
\hline Unilateral flush terminal plane & 2 & 0.5 & -4 & 1.1 & 6 & 1.6 & 1.00 \\
\hline Bilateral flush terminal plane & 144 & 38.7 & -205 & 55.1 & 349 & 93.8 & ${ }^{* *} 0.00$ \\
\hline Maxillary overjet $(\geq 6 \mathrm{~mm})$ & 7 & 1.9 & ${ }^{-} 12$ & 3.2 & 19 & 5.1 & 0.63 \\
\hline Mandibular overjet $(>0 \mathrm{~mm})$ & 2 & 0.5 & 5 & 1.3 & 7 & 1.9 & 0.70 \\
\hline Deep-bite $(\geq 50 \%$ overlap $)$ & 25 & 6.7 & 55 & 14.8 & 80 & 21.5 & ${ }^{* *} 0.03$ \\
\hline Frontal open-bite $(>0 \mathrm{~mm})$ & 2 & 0.5 & 4 & 1.1 & 6 & 1.6 & 1.00 \\
\hline Lateral open-bite & 1 & 0.3 & 2 & 0.5 & 3 & 0.8 & 1.00 \\
\hline Cross-bite (posterior) & 1 & 0.3 & 0 & & 1 & 0.3 & 0042 \\
\hline Scissor-bite & 1 & 0.3 & 0 & & 1 & 0.3 & 0042 \\
\hline
\end{tabular}

Statistical difference between males $(\mathrm{M})$ and females $(\mathrm{F}){ }^{*} \mathrm{P}<0.05, \mathrm{M}>\mathrm{F},{ }^{* *} \mathrm{P}<0.05, \mathrm{~F}>\mathrm{M}$ (Statistics: Chi-Square test and fisher's exact test)

Abnormal maxillarylabial frenum was encountered in $2.7 \%$ of the sample (Table 2 ). The data for oral habits are presented in Table3. Table 4 shows the distribution of intercanine width and spacing in the anterior segments. The sample mean for intercanine width in the maxilla was $31.1 \mathrm{~mm}(\mathrm{SD} \pm 2.72)$ and $25.3 \mathrm{~mm}$
$(\mathrm{SD} \pm 2.46)$ in the mandible. There was a significant gender difference in this trait whereby males exhibited a higher mean intercanine wid th than females in both jaws $(\mathrm{P}<0.05)$. Lack of natural spacing in the anterior segments of the maxilla (34.4\%) and mandible (33.6\%) was encountered frequently.

Table 3

Abnormal maxillary labial frenum and functional malocclusion traits in children (157 males, 215 females) ( $n=372)$

\begin{tabular}{|c|c|c|c|c|c|c|}
\hline \multirow[b]{3}{*}{ Identified feature } & \multicolumn{4}{|c|}{ Gender } & \\
\hline & \multicolumn{2}{|c|}{ Male } & \multirow{2}{*}{\multicolumn{2}{|c|}{$\begin{array}{l}\text { Female } \\
\text { No. }(\%)\end{array}$}} & & \\
\hline & No. & $(\%)$ & & & \multicolumn{2}{|c|}{$\begin{array}{l}\text { lotal } \\
\text { No. }(\%)\end{array}$} \\
\hline Abnormal maxillary labial frenum & 4 & 1.1 & 6 & 1.6 & 10 & 2.7 \\
\hline Digital sucking & 1 & 0.3 & 7 & 1.9 & 8 & 2.2 \\
\hline Mouth breathing & 2 & 0.5 & 0 & 0.0 & 2 & 0.5 \\
\hline Lip sacking or biting & 0 & 0.0 & 1 & 0.3 & 1 & 0.3 \\
\hline
\end{tabular}


Table 4

Distribution of intercanine width $(\mathrm{mm})$ and lack of natural spaces in the anterior segments of maxilla and mandible in Moshi children (157 males, 215 females) $(n=372)$

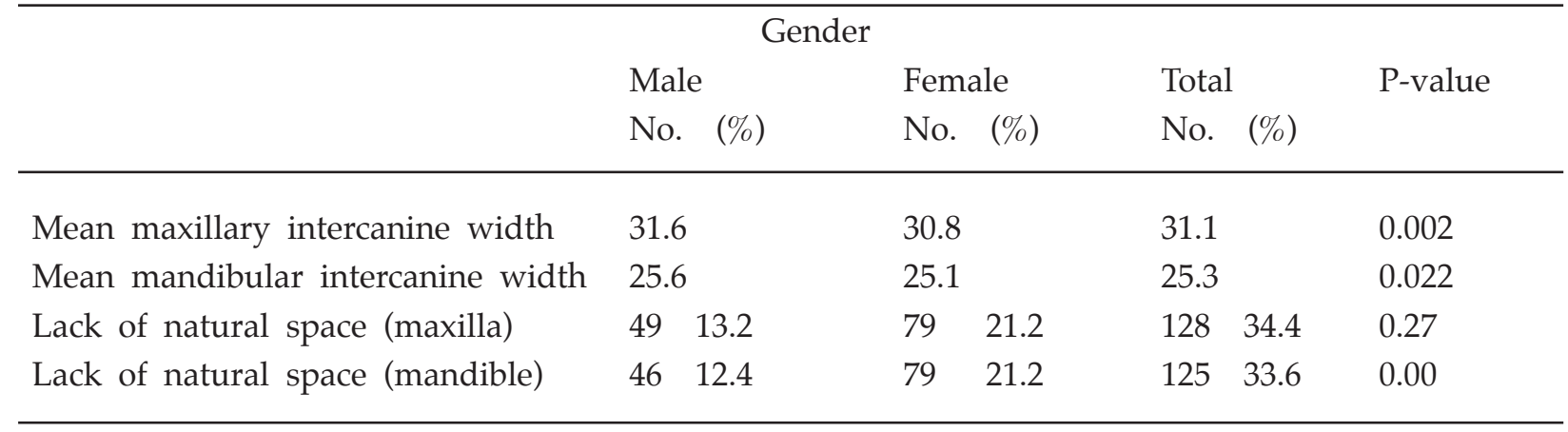

\section{DISCUSSION}

The sample in the present study constituted about $4 \%$ of all the 3-5-year-olds in Moshi municipality. The sample was selected through strict sampling procedures and would, therefore, be considered reasonably representative of children in this agegroup. Only $174(46.8 \%)$ of the parents/guardians responded to the questionnaire. Due to technical difficulties, no study models were taken in this study. The effect of this was probably the over-estimation or under-estimation of some specific occlusal traits. Inspite of these shortcomings, however, the criteria adapted for this study allowed most of the occlusal traits in the deciduous teeth and signs of oral habits to be reasonably registered. As much as possible the use of sharp instruments unfamiliar to the children was avoided in the clinical examination. The intercanine width was, therefore, measured using a miniature standardised plastic ruler. However, since children could not allow the ruler to be placed in the posterior part of their oral cavity, the inter-molar width was not measured.

The percentage of children found with malocclusion was $26.9 \%$ which was lower than those found in Kenyans (5 1\%) of similar age (4); and South Africans (53.3\%) of slightly higher age group (10). In regard to specific inter- and intra-arch occlusal traits, some important observations were evident. The results indicate that majority of the children $(93.8 \%)$ had bilateral flush terminal planes in the primary second molar relationship. Bilateral severe mesial step, distal step and mild mesial step occurred in $1.6 \%, 1.1 \%$ and $1.6 \%$ respectively. Findings of the flush terminal plane in this study were far higher than those reported for Kenyan and South African children $(4,10)$ but concurred with a previous study on Tanzanian children
(1) where it was reported that the occurrence of flush terminal plane is higher in Africans than in Caucasian children. The distal step of the primary second molar was found in $1.1 \%$ of the children. Bishara et al. (11) reported that all distal steps in the deciduous dentition develop to Class II tendency or full Class II molar relationship in the permanent dentition. Consequently it can be expected that the occurrence of the distal molar occlusion in the permanent dentition of children in Moshi will be correspondingly low.

The occurrence of increased maxillary overjet $(5.1 \%)$ and anterior cross-bite $(1.9 \%)$ were lower compared to those reported in Kenyan children of a similar age group (13\%, and 5\% respectively) (4). However, deep-bite was found in $21.5 \%$ of the present population. This was much higher than the $13 \%$ reported in Kenya (4). Although the prevalence of deep-bite can be expected to decrease somewhat from the deciduous to permanent dentition, this malocclusion trait needs to be monitored and if necessary intercepted beginning in the mixed dentition stage. Frontal open-bites occurred in $1.6 \%$ of the children. These findings were very low compared with those previously reported in Nairobi $(12 \%)$, South Africa (10.3\%) and Nigeria (5.3\%) (4, $10,12)$. Similarly these figures were low compared to previous findings $(11 \%)$ in a group of Tanzanian and Finnish children (1). The differences in these studies are probably related to ethnic variation of this trait or differences in the prevalence of oral habits. Although the occurrence of the posterior cross-bite and scissor-bite was very low in this population $(0.3 \%)$, these traits usually need mandatory interceptive orthodontic treatment. The rarity of these traits was comparable to those recorded in South Africa (10) as well as Nigeria (12). 
Generally there was a low prevalence of spacing in the anterior segments in both jaws. Since spaced anterior segments in the deciduous dentition normally develop into non-crowded anterior segments in the permanent dentition (13), it is likely that many of these children will later exhibit a degree of crowding in the anterior segments in the permanent dentition. This would be aggravated by loss of deciduous molars due to caries and subsequent failure to carry out space management due to multiple reasons including scarcity of personnel.

Abnormal maxillary labial frenum, digital sucking, mouth breathing and lip sucking / biting were rare. Digital sucking has been reported to be rare amongst African children (14, 15). The mean intercanine arch width in the upper and lower jaws in the present population was higher and the prevalence of posterior cross-bite lower than the data reported for Caucasians (16). Oral habits such as digital sucking and pacifier use, which are relatively common in the developed countries, have been shown to reduce the transverse dimensions of the maxilla $(16,17)$. In the present study there was a very low prevalence of digit sucking and the use of pacifiers is very rare in Moshi. This may be one reason for the large number of children without disharmony in the transverse dimensions in this study. Although this study has shown a moderate overall prevalence of malocclusion, it is important to point out that most of the occlusal anomalies in the deciduos dentition often manifest as malocclusion in the permanent dentition. The findings, therefore, suggest a moderate burden for preventive and interceptive orthodontic treatment. Interceptive measures would likely include management of deepbites, space and deleterious oral habits. However, seen against the lack of integrated community paediatric oral health care in Moshi, children with malocclusion or anticipated malocclusion that could otherwise benefit from preventive and interceptive orthodontic care will remain unattended.

\section{ACKNOWLEDGEMENTS}

This study was supported by the Kilimanjaro Christian Medical College of Tumaini University, Tanzania. The authors are grateful to the authorities of Moshi Municipality, Tanzania, for allowing this study to be undertaken and the children and caretakers of the nursery schools visited for their cooperation. The authors appreciate the help of disseminating information by Dr. S. Mtweve of the Community Health Department, Faculty of Medicine, Tumaini University during the preparation of this study.

\section{REFERENCES}

1. Kerosuo, H. Occlusion in the primary and early mixed dentitions in a group of Tanzanian and Finnish children. ASDC J. Dent. Child. 1990; 57: 293-298.

2. Trottman, A. and Elsbach, H.G. Comparison of malocclusion in pre-school black and white children. Am. J. Orthod. Dentofacial. Orthop. 1996; 110: 69-72.

3. Ovsenik, M., Farcnik, F.M., Korpar M. and Verdenik I. Follow-up study of functional and morphological malocclusion trait changes from 3 to 12 years of age. Eur. J. Orthodontics. 2007; 29: 523-529.

4. Kabue, M.M., Moracha, J.K. and Ng'ang'a, P.M. Malocclusion in children aged 3-6 years in Nairobi, Kenya. East Afr. Med. J. 1995; 72: 210-212.

5. Bjork, A., Krebs, A.A. and Solow B. A method of epidemiological registration of malocclusion. Acta. Odont. Scand. 1964; 22: 27-41.

6. Tandon, S., Sajid, B. and Bhat, M. Commonly occurring oral habits in children and their management. In: Tandon S. (eds.). Textbook of Pedodontics. India: Paras Medical Publisher, 2003, pp 427-460.

7. SPSS Inc. The Statistical Package for the Social Sciences. Chicago (IL): SPSS, 1997.

8. Centre for Disease Control and Prevention. Epidemiology Information. Atlanta, Georgia, 1998.

9. Landis, J.R. and Koch, G.O. The measurement of observer agreement for categorical data. Biometrics. 1977; 33:159-174.

10. Coetzeec, C.E. and Wiltshire, W. Occlusal and oral health status of a group of 3-8-year-old South Africa black children. South Afr. Dent. J. 2000; 55: 252-258.

11. Bishara, S.E., Hoppens, B.J., Jakobsen, J.R. and Kohouut, F.J. Changes in the molar relationship between the deciduous and permanent dentitions: Alongitudinal study. Am.J.Orthod.Dentofacial.Orthop. 1988; 93: 19-28.

12. Otuyemi, O.O., Sote, E.O., Isiekwe. M.C. and Jones, S.P. Occlusal relationship and spacing or crowding of teeth in the deciduous dentition of 3-4-year old Nigerian Children. Int. J. Paed. Dent. 1997; 7:155 -160.

13. Stephans, E.D.,Shaw, W.E. and Kurol, J. Management of the developing dentition. In: W.C. Shaw (eds.). Orthodontics and occlusal management. London: Butterworth-Heinemann Ltd, 1994, pp 100-122.

14. Larson, E. and Dahlin, K. The prevalence and etiology of the initial dummy and finger sucking habit. Am. J. Orthod. 1985; 87: 432-435.

15. Ngatia, E.M., Ng'ang'a, P.M., Imungi J.K., et al. Artificial sucking habits and malocclusion in three to five year-olds in Nairobi. Afr. J. Oral Hlth. Sci. 2001; 2:27-29.

16. Ogaard, B., Larrson, E. and Lindsten, R. The effect of sucking habits, cohort, sex, intercanine arch widths, and breast or bottle feeding on posterior crossbite in Norwegian and Swedish 3-year-oI children. Am. J. Orthod. Dentofacial. Orthop. 1994; 106: 161-166.

17. Warren, J. J. and Bishara, S.E. Duration of nutritive and non nutritive sucking behaviors and their effects on the dental arches in the primary dentition. Am. J. Orthod. Dentofacial Orthop. 2000; 121: 347-356. 